\title{
Study on Failure Analysis of Crankshaft Using Finite Element Analysis
}

\author{
Yoon Zuan Ang ${ }^{1}$ and Pei Xuan $\mathrm{Ku}^{1,{ }^{1}}$ \\ ${ }^{1}$ School of Computer Science and Engineering, Faculty of Innovation and Technology, Taylor's \\ University, 47500, Selangor, Malaysia
}

\begin{abstract}
Crankshaft is one of the crucial parts for the internal combustion engine which required effective and precise working. In this study, the aim of the study is to identify the stress state in the crankshaft and to explain the failure in automotive crankshaft and fatigue life of crankshaft by using finite element analysis. The 3D solid modelling of the crankshaft model was designed and developed using SolidWorks. A static structural and dynamic analysis on an L-twin cylinder crankshaft were used to determine the maximum equivalent stress and total deformation at critical locations of the crankshaft. The model was tested under dynamic loading conditions to determine fatigue life, safety factor, equivalent alternating stress and damage using the fatigue tool. The results obtained from this study indicated that the crankshaft has obvious fatigue crack which was belongs to fatigue fracture. The fatigue fracture developed was only attributed to the propagating and initiate cracks on the edges of the lubrication hole under cyclic bending and torsion. Overall, the crankshaft is safe for both static and fatigue loadings. In dynamic analysis, the critical frequency obtained in the frequency response curve should be avoided which it may cause failure of the crankshaft.
\end{abstract}

\section{Introduction}

Throughout many decades, internal combustion engine (ICE) has played a crucial role in our daily life. Research has been actively carried out to learn about the improved model for the generation. This contributes to the maximization power of ICE and minimization of fuel consumption of the automobile vehicle and air pollution to the environment, such as greenhouse effect [1]. ICE plays an important part in automotive industry due to the necessarily to transport goods and people [2].

The crankshaft is an essential mechanical part in ICE because it transforms the linear movement of the pistons into rational movement in the shaft. The crankshaft is upheld by a few main bearing journals and the rotation of the crankshaft happens because of the torque created by the connecting rod that connects with the piston to the crankshaft at crankpin [3]. The engine may be unavailable to use if the crankshaft is not working fine. The purchase and replacement would be expensive.

\footnotetext{
${ }^{*}$ Corresponding author: PeiXuan.Ku@taylors.edu.my
} 
The repair cost will not only involve the crankshaft but instead it will affect other parts as well such as the cylinder head, interfacing pole, chambers. This required extensive timeframe to fix, principally in light of the crankshaft area inside the engine [4]. The crankshaft bears complex loads and the condition of its workplace is harsh [5]. It is significant that the issues surrounding failure of crankshaft remained unsolved, and manufactures encountered numerous issues in relation to multi-axis load such as torsion and bending, the concentration of stress, the gradient of the stress and the effect of the variable amplitude load.

The advancement in technology makes the need for high speed engineering machines. As a result, there is the need for compensation between speed, efficiency and size in the development of an engine crankshaft. In the past decade, the methodology to identify stress in crankshaft can be determined using frame and beam model. With the current advance technology, the stress on crankshaft can be determined using finite element analysis (FEA). FEA involves the simulation of a physical engineering structure using a numerical technique. It involves subdividing the structure into smaller elements called mesh. Several numbers of design analysis under different constraints are performed with FEA. In designing a complex structure, computer-aided design (CAD) is used. Among the software which can be implemented to perform analysis by using computer aided engineering is ANSYS. The computer aided software is able to determine the optimal performance as well as the lifespan with regards to design failure. Harmonic analysis can be used to determine the stress due to harmonically changing loads. Endurance limit can be defined as the fatigue limit. If the stress applied is lower than the endurance limit, it will have an infinite fatigue life. The examples of more renowned theory for fatigue analysis is Soderberg and Goodman failure theories [6].

ANSYS can be implemented to analyses the crankshaft. The use of harmonic analysis is able to determine the stress and effect of components such as flywheel on a crankshaft [7]. In the previous research conducted, harmonic response for torsional deformation can be identified using transient analysis [8]. Giakoumis et al. [9] had carried out analysis on a crankshaft inertia torque harmonic for finding the torsional deformation. Talikoti et al. [10] had used the harmonic method of mode superposition to perform the transient dynamic analysis in order to determine the stiffness, stress and value of the steady state of deformation. Reddy [11] had conducted the static structural analysis to optimizing the design of the crankshaft. The static structural analysis provides the details on the deformation and total stress of the crankshaft by incorporating different raw material and design. According to Mourelatos [12] as time changes, the load applied on various area of crankshaft changes, therefore, structural dynamic analysis should be performed. During the operation of the crankshaft, it undergoes various type of vibration such as torsional, flexural, axial and couple $[13,14]$. There is different type of the crankshafts had designed and developed using various type of the CAD software such as PRO-E, CATIA-V5 or SolidWorks before conducting the analysis of the crankshaft model in ANSYS [14-17]. Most of the analysis determined that at the center of the crankshaft, it is under maximum stress and deformation located at the center of the crankpin and fillet area [18-20].

The study on the failure analysis of the L-twin crankshaft has not been reported in any open source journals. In this paper, the fatigue tool in the static structural analysis and harmonic analysis was carried out in the simulation. This is to evaluate the fatigue behavior of the crankshaft, estimate the fatigue life and determine the stress distribution state of a crankshaft in the L-twin Superquadro engine which subjected to the bending and torsional load. The Superquadro engine is a MotoGP-derived $90^{\circ} \mathrm{V} 4$ with the desmodromic timing which is one of a kind engine featuring a counter rotating crankshaft and Twin Pulse firing order. The material used in the simulation analysis is AISI 4340 forged steel and applied in the mechanical solver in the ANSYS static structural analysis and harmonic analysis. 


\section{Methodology}

\subsection{Solid modelling of the crankshaft model}

SolidWorks version 2020 software was implemented to design the 3D modelling of the automotive crankshaft. For this study, a crankshaft was used for the simulation analysis can be seen in Fig. 1. According to the geometric shapes of the commercial crankshaft, the 3D CAD modelling was designed and generated in order to obtain a more precise and accurate result during simulation analysis. In order to conduct a simulation on ANSYS platform, an IGES file for the 3D CAD modelling was required.

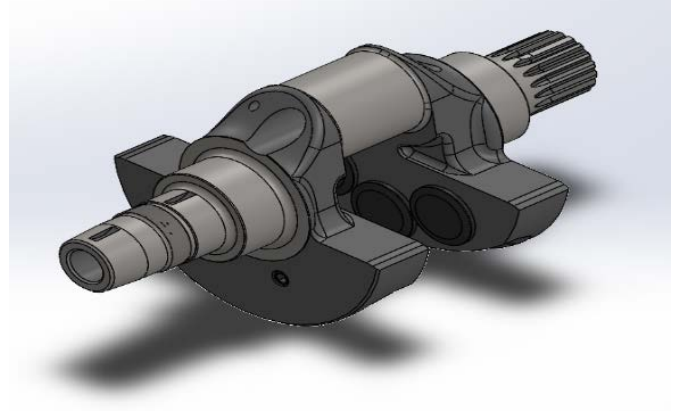

Fig. 1. Developed 3D modelling design of the crankshaft.

\subsection{Simulation of the crankshaft model}

The model developed at the initial stage was required to assign with the suitable material so it may physically behave like the actual crankshaft. The AISI 4340 normalized steel was assigned to the crankshaft model and the mechanical properties of the material is stated in Table 1. The body size was fixed on the basis of Grid Independence Test (GIT) performed on the geometry of the crankshaft. The five mesh were used in this study with different element size and the results as relation between stress and strain was plotted for each mesh with fixed solver setting and boundary conditions. Based on the GIT reported in Fig. 2, it was being observed that the difference in the plot for the element size $0.0025 \mathrm{~m}$ (Mesh 4) and $0.0001 \mathrm{~m}$ (Mesh 5) was almost nil and hence therefore the element size $0.0025 \mathrm{~m}$ was used for the further analysis such as modal analysis, harmonic analysis and fatigue analysis.

Table 1. Mechanical Properties of AISI 4340 forged steel.

\begin{tabular}{ll}
\hline Properties & Value \\
\hline Modulus of elasticity/Young's modulus $(\mathrm{Pa})$ & $2 \mathrm{E}+11$ \\
Poisson ratio & 0.32 \\
Ultimate tensile strength $(\mathrm{Pa})$ & $4.6 \mathrm{E}+8$ \\
Yield stress $(\mathrm{Pa})$ & $2.5 \mathrm{E}+7$ \\
Density $\left(\mathrm{kg} / \mathrm{m}^{3}\right)$ & 7850 \\
\hline
\end{tabular}

Fig. 3 shows the boundary conditions for the Fatigue Analysis, Modal \& Harmonic Analysis. For the boundary condition, it was being observed that the crankshaft was subjected to bending and torsional load. The crankpin is the point of contact with piston end and subjected to force transmitted by the piston due to explosion of gases inside cylinder block. 
The force acting on the crankshaft was calculated using Eq. 1 where $F_{p}, P_{\max }$ and $A$ indicates the gas force, maximum gas pressure and cross-sectional area of piston.

$$
F_{p}=P_{\max } \times A
$$

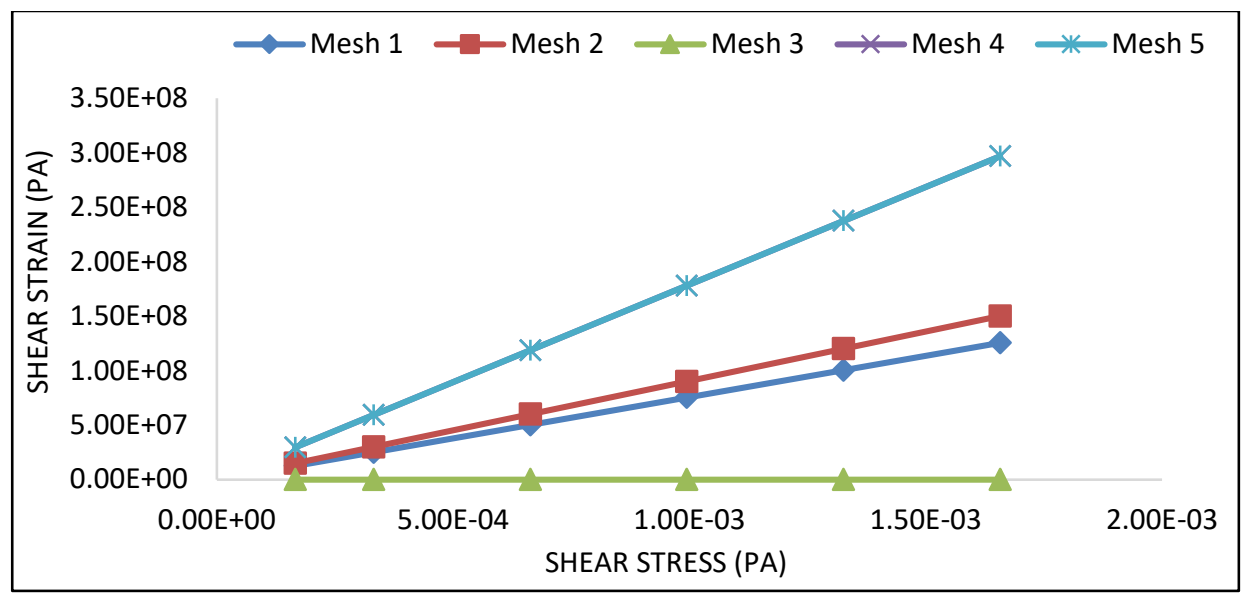

Fig. 2. Shear stress vs shear strain for five different mesh size.

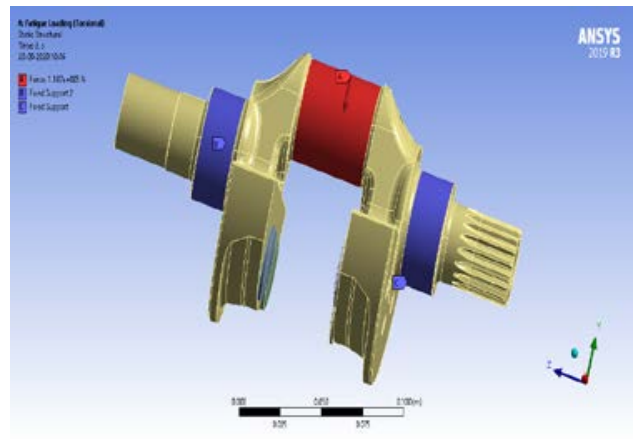

(a)

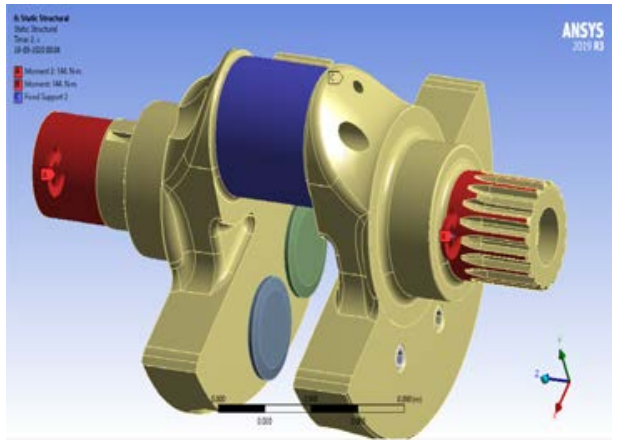

(b)

Fig. 3. Crankshaft subjected to (a) bending load $\left(\mathrm{F}_{\mathrm{t}}=118.25 \mathrm{kN}\right)$, and (b) torque (144 Nm).

When the maximum gas pressure of 112.5 bar is exerted at the piston, the force acting on the piston and transmitted to the crankshaft was calculated by using kinematics relation which the value of the force is $118.2 \mathrm{kN}$. Ducati Superquadro engine is L-twin cylinder design with $1285 \mathrm{cc}$, and $118.2 \mathrm{kN}$ is the calculated force acting on the crankpin. This is the maximum force value acting on the crankpin during power stroke.

Finite element analysis (FEA) was conducted in ANSYS 2019 R3 to determine fatigue life of the simulation model under various loading conditions. Two boundary conditions as shown in Fig. 3 were used for the fatigue life cycle evaluation. The analysis was carried out into three stages such as fatigue analysis, modal analysis and harmonic analysis. The fatigue analysis was performed using ANSYS Workbench fatigue module. For fatigue analysis, the solver was programmed for the 2 steps and 50 sub steps with large defection off and program controlled nonlinear controls. The fatigue tool was used to evaluate fatigue damage and life cycle prediction. The case setup was tested for the same boundary conditions with zero based and fully reversed loading and the selecting mean stress theory the results are computed. The selections of the mean stress theory were Goodman, Gerber and Soderberg [6]. Modal 
analysis was carried out with the objective to determine the natural frequencies of free vibrations. Ten order of natural frequency were calculated for the displacement at 10 nodes corresponds to vibration. It had provided the further background for the harmonics analysis at various loads which finally has a guiding significance in design and manufacture of carnkshafts. For harmonic analysis, the harmonic behavior of L-twin cylinder crankshaft was investigated for the bending and the torsional loading conditions. The rotating parts and subjected to fluctuating and cyclic loads were influenced with vibration which could harm the mountings and may produce high wear and tear. The crankshaft revolutions per minute (rpm) depends on the flow rate of charge inside combustion chamber, it varies from $0 \mathrm{rpm}$ to $10500 \mathrm{rpm}$ which is a very high speed for the generation of vibrations in this study. Hence, the behavior of the vibration effects are commonly analyzed by harmonic analysis. The minimum frequency and the maximum frequency of the vibration were set to $2782.1 \mathrm{~Hz}$ and $7340.7 \mathrm{~Hz}$ respectively which was obtained from the modal analysis.

\section{Results and Discussion}

The results visualization is the post processing stage which deals with the graphical representation of output values. Typically, the deformed configuration, mode shapes and distribution of stress are computed and displayed at this stage. The FEA experiment was conducted on the 3D simulation model discretized with the element size $0.0025 \mathrm{~m}$ for the boundary conditions and solver setup discussed, and the results were reported in this segment. The simulation was carried out for the two different loading conditions such as crankshaft subjected to bending load and crankshaft subjected to maximum torque. In this research, full reversed loading and Gerber theory were selected for the fatigue analysis.

\subsection{Fatigue analysis of crankshaft subjected to bending load}

The static structural case was solved at four different load values acting on the crankshaft, whereas the maximum was considered to be $118.2 \mathrm{kN}$. Von-Mises stresses was taken as failure criteria for ductile metal. Fig. 4(a) presents the stress value as the color map representation for von-Mises stress. It was observed that the location of maximum stress is located at radius at end of the crankpin. The maximum value of stress was reported as 274.21 MPa at the crankpin. For the maximum loading condition, the equivalent stress values are below the yield stress of $460 \mathrm{MPa}$. The crankshaft had a higher chance of failure at this location under cyclic load. The material also had a tendency to shear due to complex loading conditions. Fig. 4(b) shows the color map representation of shear stress concentration throughout the crankshaft. The maximum value of shear stress was calculated as $42 \mathrm{MPa}$ near the corners of the crankpin. For the maximum loading condition, the shear stress values are below the yield stress of $265 \mathrm{MPa}$.

The stress-strain curve for equivalent stress was plotted to check the response of the bending load as shown in Fig. 5. The curve had shown the linear relationship of stress vs strain, which was plotted on the logarithmic x-scale to represent the skewness towards the large values. The maximum value of stress calculated from the analysis is under safe yield value (460 MPa). To formulate the real dynamic behavior of crankshaft, the four load values were assigned at the same point, and the response was analyzed. It was observed that during $360^{\circ}$ of rotation, the crankshaft was subjected to different loads at different angles, which was a very complex situation to simulate. 


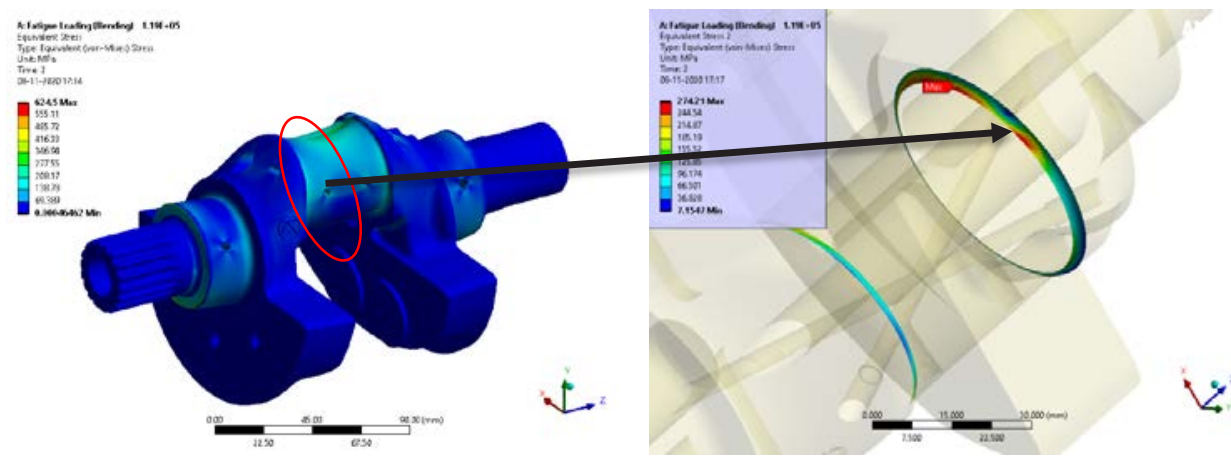

(a)

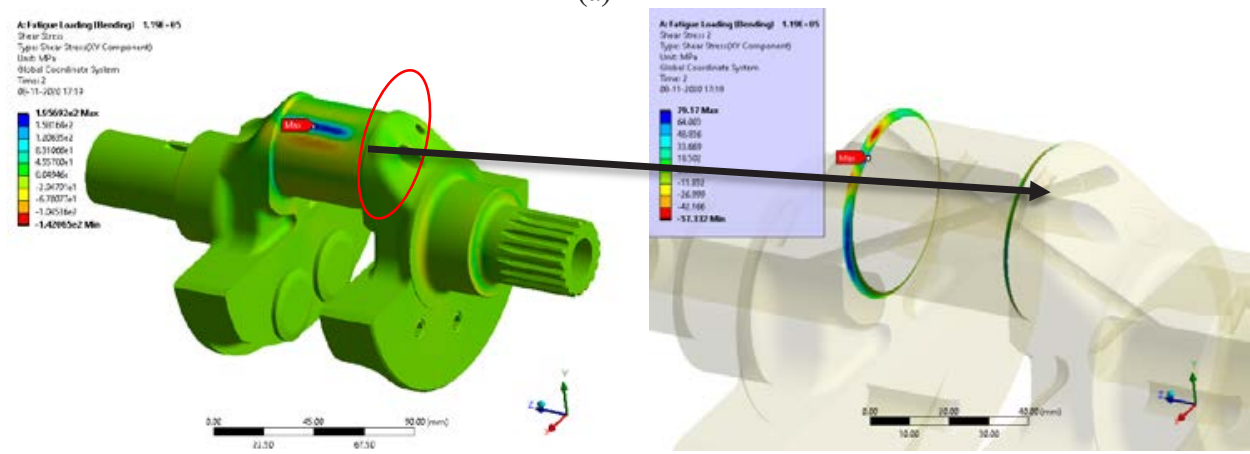

(b)

Fig. 4. Static structural cases. (a) Equivalent (von-Mises) stress and (b) Shear stress.

Von-Mises equivalent stress vs equivalent strain was plotted at different load values to determine the yield value or fracture as shown in Fig. 6. The curve response was found to be a linear relationship. The abscissa was set to the logarithmic scale, and, for the same strain value, the stress generated in the crankshaft was plotted. The maximum stress value developed for the load of $118.2 \mathrm{kN}$ was reported to be $274.21 \mathrm{Mpa}$, which is under the permissible limit and the fatigue life of $1.61 \mathrm{e}+9$ hours was evaluated.

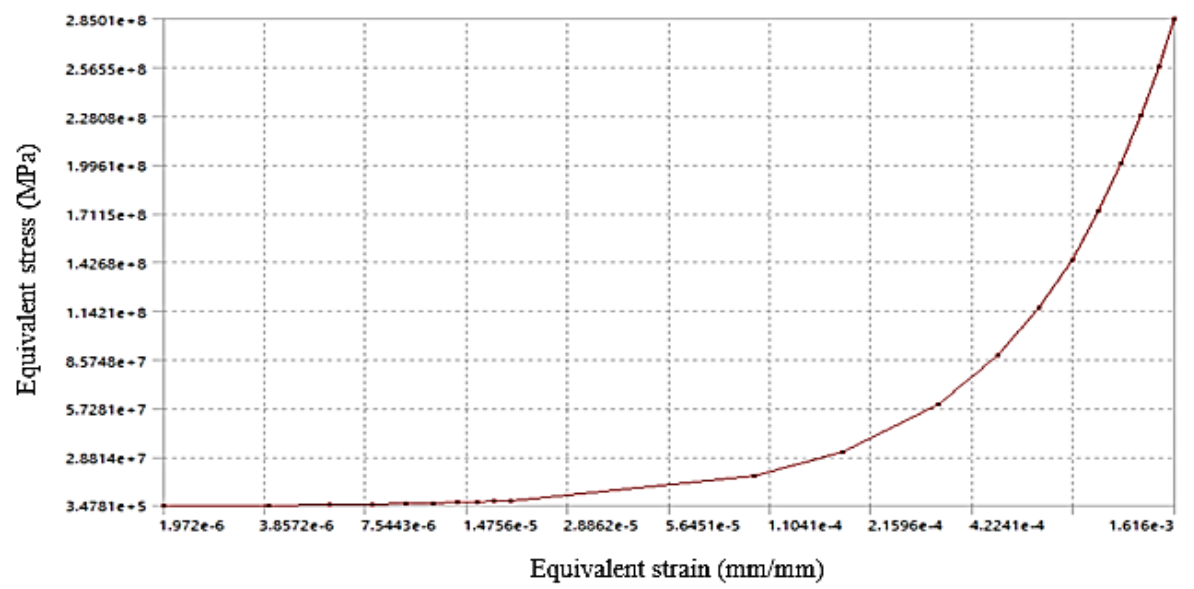

Fig. 5. Equivalent (von-Mises) stress vs equivalent strain 


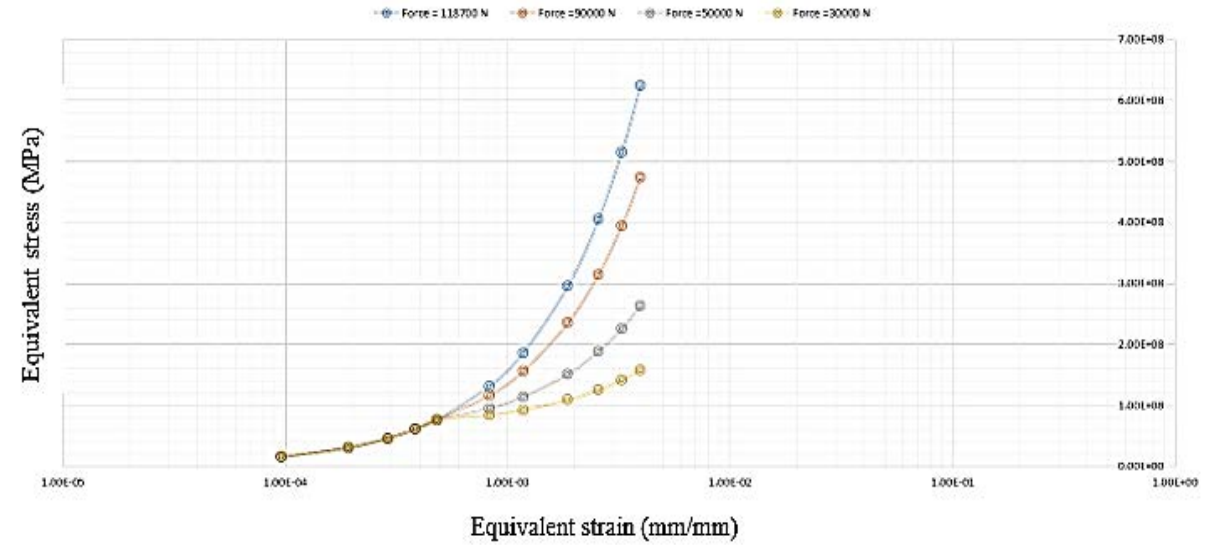

Fig. 6. Equivalent von-Mises stress vs equivalent strain at different loads.

The fatigue analysis was performed on the crankshaft for evaluating life cycle, crack propagation, and yield strength, which can be used for product integrity and optimization. The fatigue tool provided in ANSYS structural was used to evaluate the fatigue life, fatigue damage, safety factor, and alternating stress. The crankshaft was tested for the bending load of $118.2 \mathrm{kN}$ with fixed ends. Table 2 and Fig. 7 indicate the results obtained from the fatigue test. Fatigue life indicated the available for given fatigue analysis which represent the number of cycles until the part will fail due to fatigue.

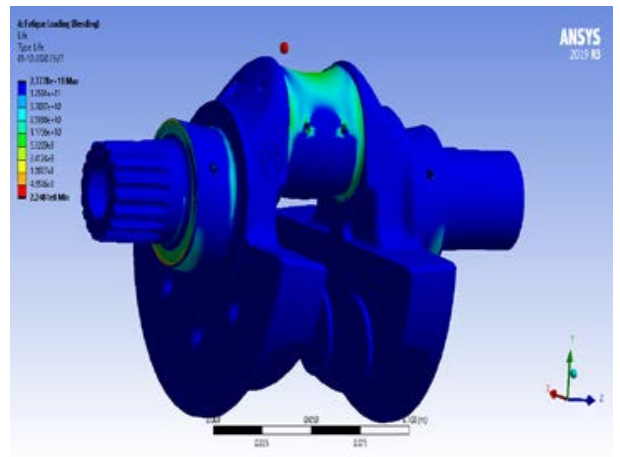

(a)

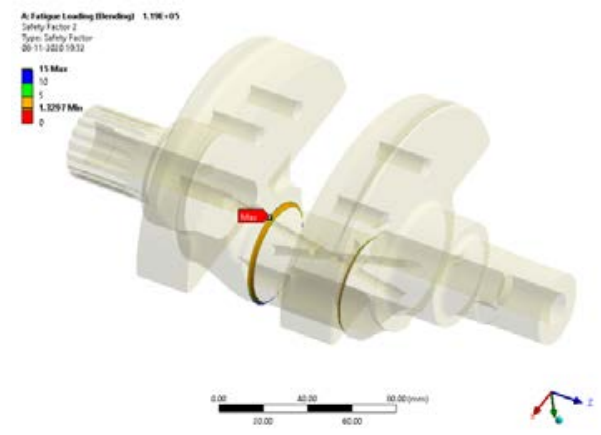

(c)

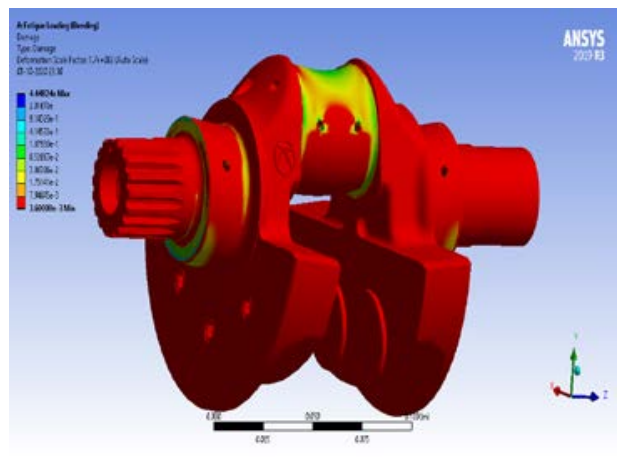

(b)

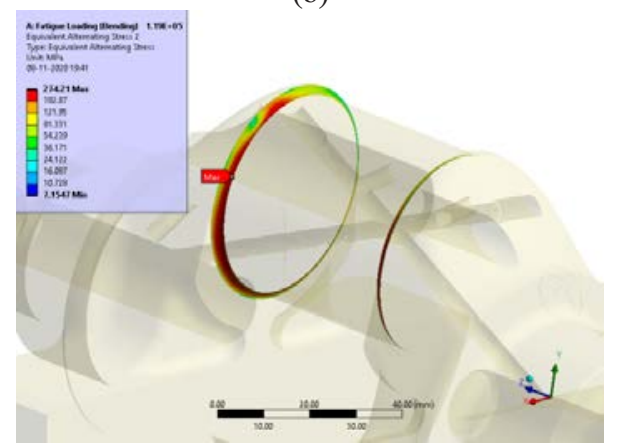

(d)

Fig. 7. Fatigue analysis parameters: (a) Fatigue life in hours, b) Fatigue damage, c) Fatigue safety factor, d) Fatigue equivalent alternating stress 
The crankshaft fatigue life is shown in Fig. 7(a). Fig. 7(b) shows the contour plot of the fatigue damage, which is basically the design life or available life of the component. For the fatigue damage, the value greater than 1 represents the failure of the component before the design life is reached. It was observed that the failure take place at the dislocation, which is the point of maximum stress concentration. Fig. 7(c) shows the fatigue factor of safety with respect to the fatigue failure at a given design life. The maximum factor of safety is 15 , the value of less than one results in the failure of the component before design life. Due to the fatigue load, the equivalent alternating stress was developed in the component (Fig. 7(d)). The alternating stress had illustrated the maximum and minimum values for the cyclic load. The crankpin had the portion subjected to maximum stress and the possibility of failure. The maximum stress life of the crankshaft for the high cycle loading was determined as $1.61 \mathrm{e}+9$ hours, under the alternating stress of $18.131 \mathrm{MPa}$. The maximum fatigue damage reported as $1.88 \mathrm{e}-1$ at the crankpin, which is less than one and ensures that the product durability. For the fatigue sensitivity, the change in fatigue results changes as the function of the loading at the critical location of the crankshaft model. The results show the decrease in fatigue life as the load value was increased from $50 \%$ to $150 \%$.

Table 2. Fatigue life cycle assessment

\begin{tabular}{ll}
\hline Factors & Value \\
\hline Minimum life for the maximum bending load of 118.2kN (hours) & $1.61 \mathrm{e} 9$ \\
Damage & 0.47562 \\
Safety factor & 0.58388 \\
Equivalent alternating stress $(\mathrm{Pa})$ & 1.8131 \\
\hline
\end{tabular}

\subsection{Fatigue analysis of crankshaft subjected to torsional load}

The second case was formulated with the crankshaft subjected to both bending and torsional stress. A torque of $144 \mathrm{Nm}$ was applied at the extreme ends and the crankpin was fixed. The load of $14 \mathrm{kN}$ was applied for the one-time step. Fig. 8 illustrated the color map representation of shear stress concentration throughout the crankshaft. The stress-strain curve plotted for the response of crankshaft was present in Fig. 9, the results validated the forces calculated at the crankpin. The color map of the crankpin and the fillet areas are the locations of high-stress concentration and with the higher possibility of failure. The results of the fatigue life cycle assessment were as shown in Table 3.

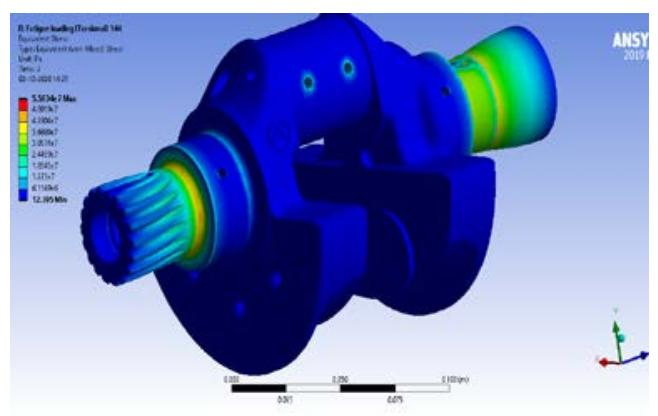

(a)

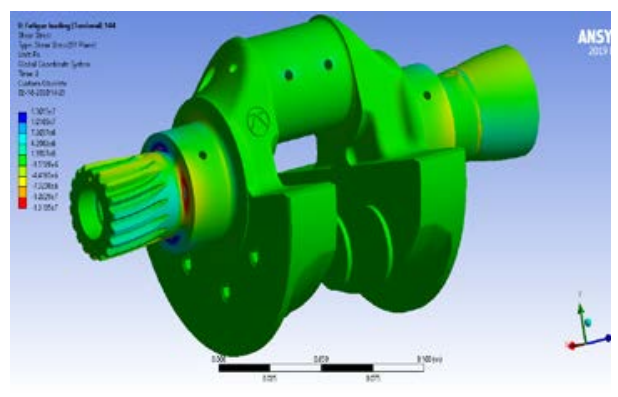

(b)

Fig. 8. a) Equivalent (von-Mises) stress, b) Shear stress. 


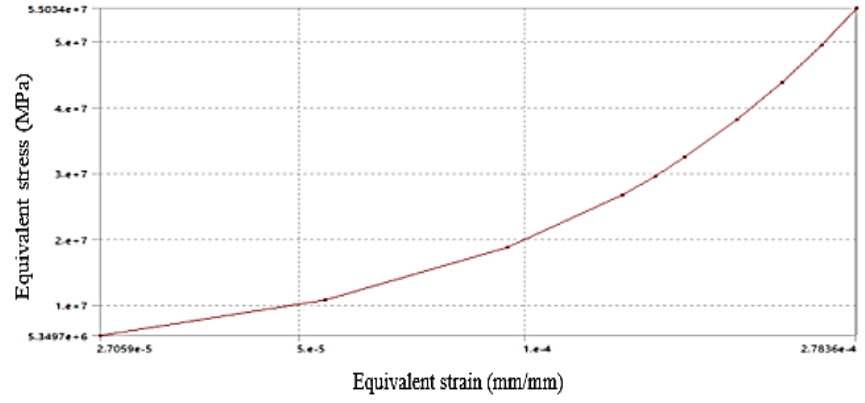

Fig. 9. Equivalent (von-Mises) stress vs equivalent strain.

Table 3. Fatigue life cycle assessment

\begin{tabular}{ll}
\hline Factors & Value \\
\hline Minimum life for the maximum torque of 144 Nm (hours) & $2.7778 \mathrm{e}+11$ \\
Damage & 0.0036 \\
Safety factor & 5.1873 \\
Equivalent alternating stress $(\mathrm{Pa})$ & $4.2865 \mathrm{e}+7$ \\
\hline
\end{tabular}

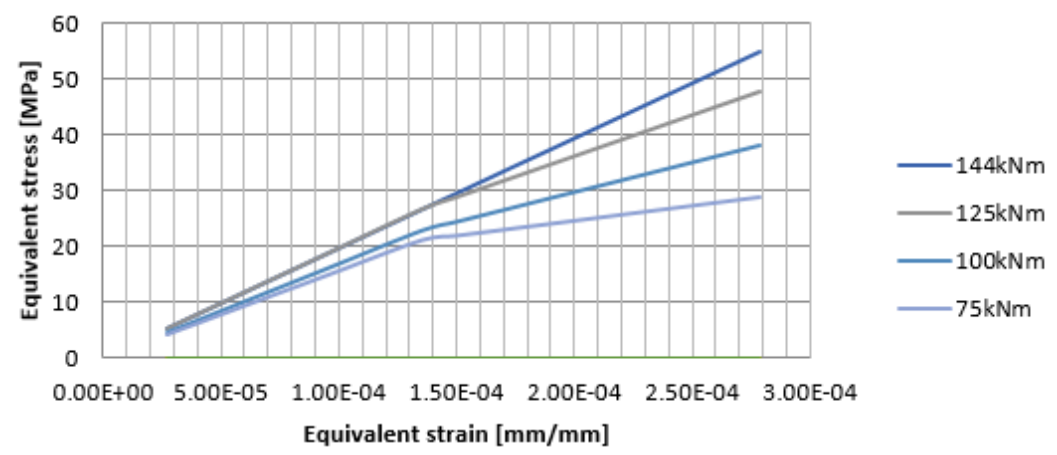

Fig. 10. Equivalent von-Mises stress-strain relationship for the different torque values.

To formulate the dynamic loading condition, four different torque values were assigned to the crankshaft, and the response was reported. The stress-strain curve for equivalent vonMises stress was shown in Fig. 10 indicates the linear relationship, and the maximum value was calculated as $5.503 \mathrm{e}+7 \mathrm{~Pa}$, which is under safe permissible yield stress and the fatigue life of $1.61 \mathrm{e}+10$ hours was evaluated.. The maximum value of shear stress was calculated as 15.6 MPa, which near the corners of the crankpin. The observed values obtained were close enough to the results obtained from the crankshaft subjected to bending load. The results obtained for both the cases of loading conditions ensure the dynamic behavior of the crankshaft. The maximum torque applied to the crankshaft was $144 \mathrm{Nm}$, and it was decreased to $75 \mathrm{Nm}$. This was to check the response of stress-strain curve and to evaluate stress life. The fatigue life was calculated $2.778 \mathrm{e}+11$ hours in the absence of a bending load at the crankpins. The crankpin and the corners were the high-stress concentration zone and with the maximum possibility of crack formation and failure. However, in actual practice, the crankshaft is subjected to both bending and torsional loads, and it has to deal with the fluctuating loads with shocks as well, which depends on the engine operating conditions. 


\subsection{Harmonic Analysis of Crankshaft}

The vibrational excitation of any structure was analyzed using the modal analysis. The technique was used to determine the vibrational characteristics like natural frequency and mode shapes. The harmonic analysis was performed at the various frequency of vibration obtained from the modal analysis. The harmonic analysis of the crankshaft was carried out by using finite element software such as ANSYS workbench. The advantage of using a finite element software package was that mode shapes could be accurately visualized and simulated. So, the stress and deformation in the crankshaft could be precisely calculated. The major and the critical locations of the crankshaft can be identified, where the possibility of failure could arise and suggest some suitable amendments may be performed on the design of the crankshaft according to constraints and boundary conditions. The various value of deformation and stress obtained from the analysis were shown in Fig. 11. The various graphs were plotted to represent the behavior of the crankshaft under a speed of $10500 \mathrm{rpm}$ of the engine.

Fig. 11 shown the equivalent von-Mises stress developed at the frequency of $7340 \mathrm{~Hz}$, which is the highest frequency obtained at the modal analysis for bending as well as torsional load. While applying the bending load, the two extreme ends of the crankshaft were kept fixed, and the load was applied at the crankpin. Fig. 11 (a) illustrated the color map for the equivalent stress values when the crankshaft was subjected to the vibration of $7340 \mathrm{~Hz}$. The maximum deformation was developed in the counterweight section at stress $8300 \mathrm{MPa}$. The portion of the crankshaft close to the counterweights was subjected to maximum stress and the possibility of crack formation.

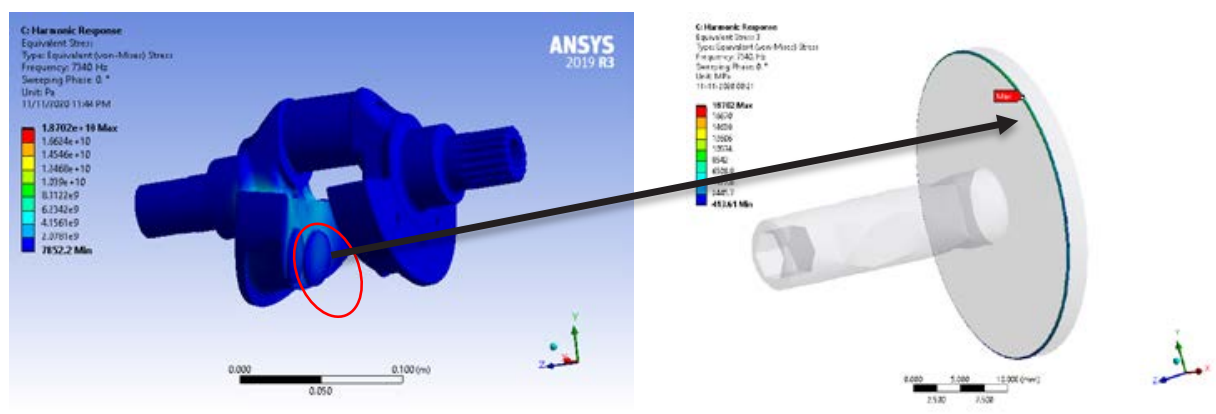

(a)

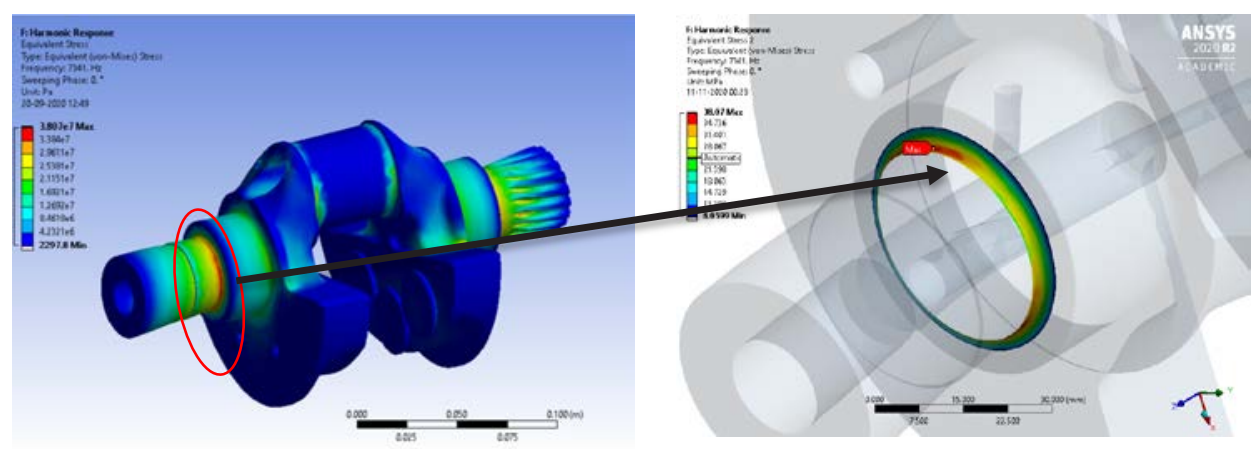

(b)

Fig. 11. a) Equivalent (von-Mises) stress for the crankshaft subjected to (a) pure bending load and (b) maximum torque. 
Fig. 11(b) indicated the equivalent von-Mises stress developed in the crankshaft when subjected to torsional load. The fillet around the shaft near journal bearing and crankpin were the locations of high stress represented in red color. The maximum value of stress was observed to be $33.8 \mathrm{MPa}$ in the fillet region. The frequency responses for the normal stress values and total deformation were found in Fig. 12, 13 and 14. The peak value at the curve was the indication of the frequency of vibration is close to resonance frequency and cause the failure of component hence, therefore such frequency value must be avoided by introducing necessary damping mechanism.

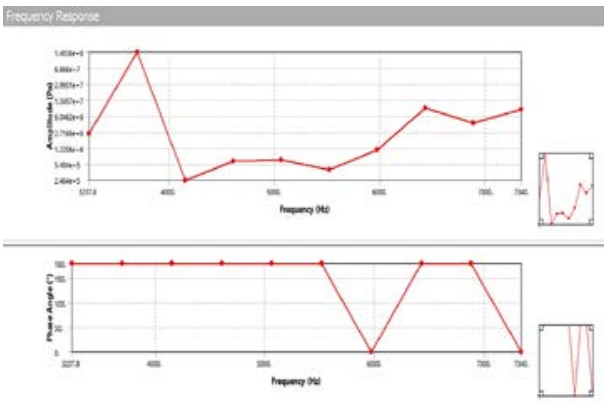

(a)

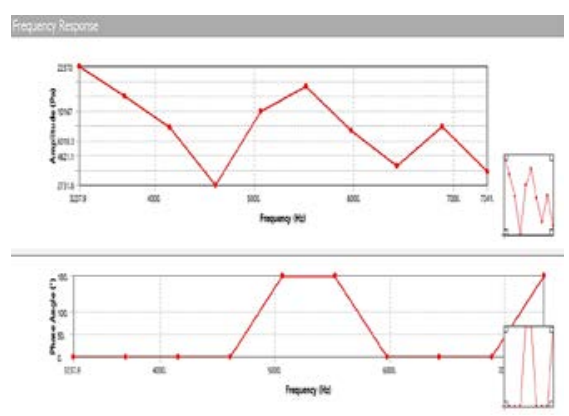

(b)

Fig. 12. Harmonic frequency vs normal stress for (a) force $\left(F_{t}=118.2 \mathrm{kN}\right)$ and torque $(\tau=144 \mathrm{Nm})$ acting at the crankpin.

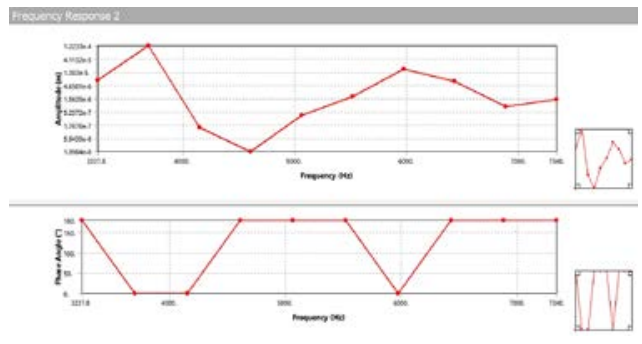

(a)

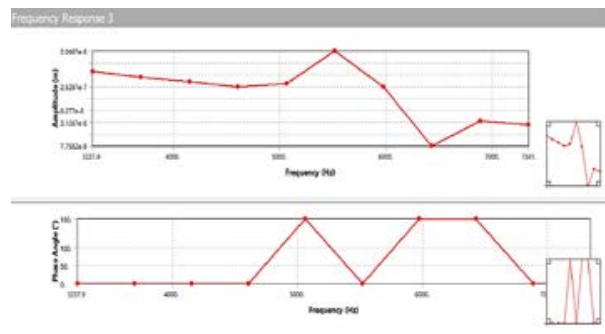

(b)

Fig. 13. Harmonic frequency vs directional deformation for (a) force $\left(\mathrm{F}_{\mathrm{t}}=118.2 \mathrm{kN}\right)$ and torque $(\tau=144 \mathrm{Nm})$ acting at the crankpin.

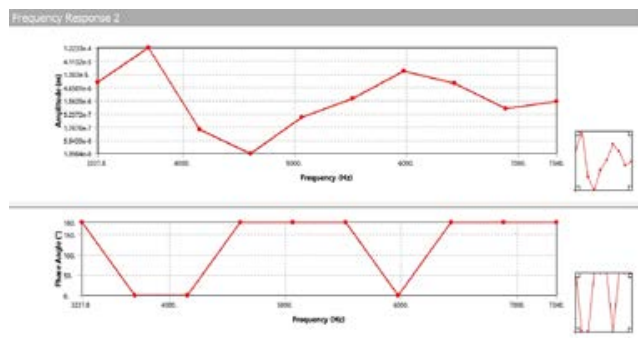

(a)

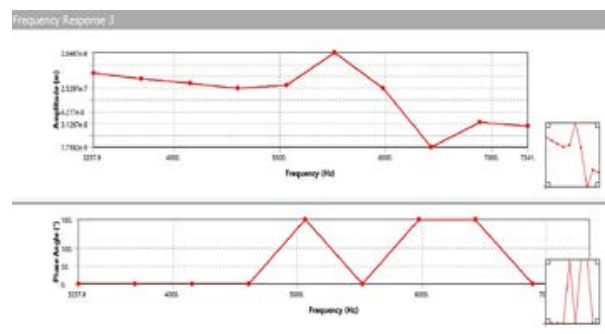

(b)

Fig. 14. Harmonic phase response including response of force for (a) force $\left(F_{t}=118.2 \mathrm{kN}\right)$ and (b) torque ( $\tau=144 \mathrm{Nm}$ ) acting at the crankpin.

Fig. 12 shows the normal stress plot at the frequency range of $3237 \mathrm{~Hz}$ to $7340 \mathrm{~Hz}$ for the crankshaft which is subjected to bending load and torsional load respectively. The peak value of normal stress was generated at the frequency of $3780 \mathrm{~Hz}$ for the bending load and 
at the frequency of $3237 \mathrm{~Hz}$ for the torsional load. The material has the tendency to shear undergone the directional deformation. The maximum deformation occurs at the frequency of $3780 \mathrm{~Hz}$ for the bending load and at the frequency of $5843 \mathrm{~Hz}$ when the crankshaft subjected to torsional load as shown in Fig. 13. The corresponding phase angle response and the force response are shown in Fig 14. The operating frequency range could be decided from the results obtained from the harmonic analysis and the required modifications can be made in the design to improve the design life. The critical frequency obtained in the frequency response curve, which is highlighted in the square at the bottom right must be avoided as it may cause the failure of the component.

\section{Conclusion}

The aim of the research is to study the fatigue failure analysis of crankshaft using finite element analysis. The stress-strain curve was a linear relationship obtained for this analysis to ensure that the maximum stress developed is under the safe permissible range of yield values. The results reported from this analysis stated that the failure began at the fillet region on the lubrication hole and this was caused by the high bending stress concentration. The high stress concentration zone was the focus of this study as its location of failure, the crankpin and the corners were evaluated as the high stress concentration and fatigue failure zone in this study.

Dynamic results proved that the design of the crankshaft statically safe failed under the dynamic condition for both the loading conditions of the crankshaft. The natural frequency under fixed boundary conditions was found to be in the range of $2782 \mathrm{~Hz}$ to $7340 \mathrm{~Hz}$. Besides, the harmonic analysis shows that the maximum stress and deformation appeared at the web edge of the counterweight and the maximum stress intensity appeared at the fillets between the crankshaft journal and crankpin. The maximum stress intensity developed at the fillet region did not deviate from the design limit of the original crankshaft and theoretical values.

\section{References}

1. H. Bayrakçeken, S. Tasgetiren, F. Aksoy, "Failures of single cylinder diesel engines crank shafts," Eng. Fail. Anal., 14, 725 (2007)

2. S. K. Bhaumik, R. Rangaraju, M. A. Venkataswamy, T. A. Bhaskaran, M. A. Parameswara, "Fatigue fracture of crankshaft of an aircraft engine," Eng. Fail. Anal., 9, 255 (2002)

3. J. A. Becerra, F. J. Jimenez, M. Torres, D. T. Sanchez, E. Carvajal, "Failure analysis of reciprocating compressor crankshafts," Eng. Fail. Anal., 18, 735 (2011)

4. K. S. Choi, J. Pan, "Simulations of stress distributions in crankshaft sections under fillet rolling and bending fatigue tests," Int. J. Fatigue, 31, 544 (2009)

5. W. Y. Chien, J. Pan, D. Close, S. Ho, "Fatigue analysis of crankshaft sections under bending with consideration of residual stresses," Int. J. Fatigue, 27, 1 (2005)

6. A. C. Ugural, Mechanical Engineering Design: Third Edition (CRC Press, 2020)

7. K. Vijaykumar, U. Manoj, T. Girish, M. Rajesh, S. Girish, "Crankshaft design optimization to improve dynamic balancing and fatigue strength," Int. J. Automot. Eng., 6, 59 (2015)

8. F. Montazersadgh, A. Fatemi, "Dynamic Load and Stress Analysis of a Crankshaft. SAE Technical Paper 2007-01-0258," in SAE World Congress, (2007) 
9. E. Giakoumis, C. Rakopoulos, A. Dimaratos, "Study of crankshaft torsional deformation under steady-state and transient operation of turbocharged diesel engines," P. I. Mech. Eng. K-J. Mul., 222, 17 (2008)

10. B. Talikoti, S. N. Kurbet, V. V. Kuppast, M. Arvind, "Harmonic analysis of a two cylinder crankshaft using ANSYS," in 2016 International Conference on Inventive Computation Technologies (ICICT), 1 (2016)

11. V. M. Reddy, T. V. Devi, "Design, analysis and optimization of a 6 cylinder engine crank shaft," Int. J. Mod. Eng. Res. Technol., 4, 30 (2013)

12. Z. P. Mourelatos, "A crankshaft system model for structural dynamic analysis of internal combustion engines," Comput. Struct., 79, 2009 (2001)

13. P. D. Shah, K. K. Bhabhor, "Parametric optimization of four cylinder engine crankshafts," Int. J. Eng. Sci. Invent, 3, 38 (2014)

14. K. Thriveni, B. J. Chandraiah, "Modeling and analysis of the crankshaft using ANSYS software," Int. J. Comput. Eng. Sci., 3, 84 (2013)

15. R. Garg, S. Baghla, "Finite element analysis and optimization of crankshaft design," Int. J. Eng. Manag. Res., 2, 26 (2012)

16. W. Homik, "Diagnostics, maintenance and regeneration of torsional vibration dampers for crankshafts of ship diesel engines," Polish Marit. Res., 17, 62 (2010)

17. G. Yingkui, Z. Zhibo, "Strength Analysis of Diesel Engine Crankshaft Based on PRO/E and ANSYS," in 2011 Third International Conference on Measuring Technology and Mechatronics Automation, 362 (2011)

18. J. Brahmbhatt, A. Choubey, "Design and analysis of crankshaft for single cylinder 4stroke diesel engine," Int. J. Adv. Res. Technol., 1, 88 (2012)

19. R. Deshbhratar, Y. Suple, "Analysis and optimization of crankshaft using FEM," Int. J. Mod. Eng. Res., 2, 3086 (2012)

20. J. Meng, Y. Liu, R. Liu, "Finite element analysis of 4-cylinder diesel crankshaft," Int. J. Image Graph. Signal Process., 3, 22 (2011) 